\title{
Oligofructose supplementation during pregnancy and lactation impairs offspring development and alters the intestinal properties of 21-d-old pups
}

Laís Vales Mennitti ${ }^{1}$, Lila Missae Oyama ${ }^{3}$, Juliana Lopez de Oliveira ${ }^{3}$, Ana Claudia Losinskas Hachul ${ }^{3}$, Aline Boveto Santamarina ${ }^{3}$, Aline Alves de Santana ${ }^{3}$, Marcos Hiromu Okuda ${ }^{3}$, Eliane Beraldi Ribeiro ${ }^{3}$, Claudia Maria da Penha Oller do Nascimento ${ }^{3}$ and Luciana Pellegrini Pisani ${ }^{2^{*}}$

\begin{abstract}
Background: Previously, we showed that the intake of trans fatty acids during pregnancy and lactation triggers a pro-inflammatory status in the offspring. On the other hand, prebiotics can alter the intestinal environment, reducing serum lipopolysaccharides (LPS) concentrations. This study evaluated the effect of the oligofructose $10 \%$ diet supplementation in the presence or absence of hydrogenated vegetable fat during pregnancy and lactation on the development, endotoxemia and bacterial composition of 21-d-old offspring.

Methods: On the first day of pregnancy rats were divided into four groups: control diet (C), control diet supplemented with 10\% oligofructose (CF), diet enriched with hydrogenated vegetable fat, rich in TFA (T) or diet enriched with hydrogenated vegetable fat supplemented with 10\% oligofructose (TF). Diets were maintained during pregnancy and lactation. At birth, 7th, 14th and 21th, pups were weighed and length was measured. Serum concentrations of LPS and free fatty acids (FFA) were performed by specific kits. Bacterial DNA present in faeces was determined by real-time PCR. Data were expressed as mean \pm standard error of the mean and the statistical analysis was realized by ANOVA two-way and ANOVA for repeated measures. $\mathrm{p}<0.05$ was considered significant.

Results: We observed that the oligofructose (10\%) supplementation during pregnancy and lactation reduced body weight, body weight gain, length and serum FFA in the CF and TF group compared to $C$ and T group respectively, of the 21-day-old offspring, accompanied by an increase in serum LPS and genomic DNA levels of lactobacillus spp. on faeces of the CF group in relation to $C$ group.

Conclusion: In conclusion, dam's diet supplementation with 10\% of oligofructose during pregnancy and lactation, independent of addition with hydrogenated vegetable fat, harms the offspring development, alters the bacterial composition and increases the serum concentrations of lipopolysaccharides in $21 \mathrm{~d}$-old pups.
\end{abstract}

Keywords: Hydrogenated vegetable fat, Oligofructose, Corporal composition, Lipopolysaccharides, Lactobacillus spp, Pregnancy, Lactation

\footnotetext{
* Correspondence: lucianapisani@hotmail.com

${ }^{2}$ Departamento de Biociências, Instituto de Saúde e Sociedade, Universidade Federal de São Paulo, Rua Silva Jardim, 136, Térreo, Vila Mathias, Santos, SP, Brazil

Full list of author information is available at the end of the article
} 


\section{Background}

Maternal nutrition during pregnancy and lactation plays a crucial role in the development foetal and newborn until adulthood, possibly influencing foetal "programming" by epigenetic modifications that can alter gene expression and permanently affect the structure and function of several organs and tissues, thereby inducing phenotypic changes [1-4]. Recently, the concept of foetal "programming" has been applied to examine possible beneficial or adverse influences of the maternal nutritional supply to the foetus and the newborn until later life [5].

During critical periods of foetal development, inadequate maternal nutrition may alter the physiologic and morphologic development of the foetus and the newborn, increasing the individual's susceptibility to develop metabolic diseases in adulthood, such as cardiovascular disease, diabetes and hypertension [1-4]. A positive correlation between the development of metabolic disease and the production of pro-inflammatory cytokines is known $[6,7]$.

Previous studies from our laboratory demonstrated that the maternal intake of hydrogenated vegetable fats that are rich in trans fatty acids (TFA) during pregnancy and lactation triggers changes in the lipid metabolism and decreases serum levels of adiponectin in 21-d-old pups. These findings were accompanied by increases in TNF- $\alpha$ gene expression and the protein expression of TRAF-6 (TNF receptor-associated factor 6 ) in the adipose tissue $[8,9]$. Furthermore, the authors reported that the consumption of TFA during lactation induces the development of metabolic disorders, including insulin resistance and the increased gene expression of plasminogen activator inhibitor type-1 (PAI-1) in the adipose tissue of the adult offspring [10,11]. PAI-1 is a pro-inflammatory adipokine produced mainly, in the visceral adipose tissue and vascular endothelium under influence of TNF- $\alpha$, insulin, free fatty acids (FFAs) and glucocorticoids $[12,13]$. Elevated PAI-1 serum concentrations (eg. in obesity) are associated with pro-thrombotic effects, which increase the risk for cardiovascular disease [13,14].

Complementary results by Pimentel et al. showed that the increase in hypothalamic concentrations of IL-6, TNF- $\alpha$ and IL1- $\beta$ contributed to the hypothalamus inflammation and impaired satiety control of $90-\mathrm{d}$-old pups from dams fed a diet rich in TFA during pregnancy and lactation [15].

On the other hand, several studies in humans and animals suggest that prebiotics and dietary fibres, such as oligofructose (OF), fructooligosaccharides (FOS) and inulin, can influence the glucose and lipid metabolism, specifically by reducing the serum concentrations of glucose, triacylglycerol (TG) and cholesterol [16-19]. OF, FOS and inulin are members of the inulin-type fructans group and are naturally present in many fruits and vegetables, including onions, bananas, artichokes, garlic and leeks [20-22]. Particularly, OF is a combination of "non-digestible" oligosaccharides commonly obtained by the partial enzymatic hydrolysis of chicory root inulin and is linked by $\beta(2 \rightarrow 1)$ linkages of fructosyl units, sometimes ending with a glucosyl unit $[16,20,21]$. OF and FOS are considered synonyms for inulin-type fructans with a maximum degree of polymerisation (DP) of less than 10 [16].

Furthermore, it is known that the human gastrointestinal tract enzymes only recognise $\alpha$-glycosidic bonds; therefore OF and other inulin-type fructans that bear a $\beta$ configuration are hydrolysed and fermented by colonic microbiota, with health benefits to the host [20,22-25]. Thus, inulin-type fructans are considered dietary fibres and prebiotics $[20,23,26]$.

Mammal's intestine has a microbial community consisting for approximately $10^{12}$ bacteria per $\mathrm{g}$ of intestinal content and its composition may vary according to some factors, such as: dietary nutrients, diseases and antibiotics therapy $[23,27,28]$. The mammal's intestinal microbiota is composed for bacteria belonging to three phyla: gram-negative Bacteroidetes(eg Bacteroides), gram-positive Actinobacteria (eg Bifidobacteria) and gram-positive Firmicutes (eg. Lactobacillus, Clostridium, Bacillus and Mycoplasma) [27,29]. The phyla Firmicutes and Bacteroidetes are numerically dominant in the human intestine [27]. Kim et al. demonstrated an increase of Firmicutes, accompanied by a decrease of Bacteroidetes and Bifidobacteria in mice fed high-fat diet for 8 weeks [30].

Hyperlipidic diets, especially those rich in saturated fatty acid, increase endotoxemia through the translocation of lipopolysaccharides (LPS) found in the external cellular membranes of gram-negative intestinal bacteria [31]. LPS-induced TLR-4 (Toll-like receptor 4) activation contributes to systemic inflammation by inducing the secretion of pro-inflammatory cytokines [32]. Likewise, elevated plasma concentrations of FFAs are capable of utilising the TLR-4 pathway and activating the NF-kB pathway to induce pro-inflammatory cytokine expression [33-35]. In contrast, end products of prebiotic fermentation by the colonic bacteria, especially short chain fatty acids (SCFA - acetate, propionate and butyrate), can alter the intestinal environment through the decrease of colonic $\mathrm{pH}$ and the alteration of the bacterial population (mainly bifidobacteria and lactobacillus) and intestinal permeability, thereby reducing the migration of LPS to blood circulation $[22,32,36]$.

Maternal intake of prebiotics and dietary fibres during pregnancy and lactation is considered important and beneficial for the mother and the offspring, from birth through later life. In particular, butyrate, one of the end products of oligosaccharide fermentation, is a histone 
deacetylase inhibitor, which can reactivate silent genes by epigenetic modifications. These effects on gene activity would be beneficial in the long term [37,38]. Additionally, the authors suggest that maternal intestinal microbiota function directly in the bacterial colonisation and intestinal properties of newborns and infants because human maternal milk presents a large variety and amount of oligosaccharides at concentrations ranging from 10 to $20 \mathrm{~g} / \mathrm{L}$ $[39,40]$. It is also believed that some strains of bacteria present in the maternal gut are transferred from the mother to the newborn through the maternal milk [41]. The aim of the present study was to evaluate the effect of a dietary supplementation of $10 \%$ OF during pregnancy and lactation in the presence or absence of hydrogenated vegetable fat on the development, endotoxemia and bacterial composition of 21-d-old offspring.

\section{Materials and methods}

\section{Animals and treatments}

The experimental research committee of the Universidade Federal de São Paulo approved all procedures for the care of the animals used in this study and followed international recognised guidelines (CEUA protocol n737014). The rats were kept under controlled conditions of light (12-h light/12-h dark cycle with lights on at 07:00) and temperature $\left(24 \pm 1^{\circ} \mathrm{C}\right)$, with ad libitum water and food. Three-month-old female Wistar rats (four animals in each group) were left overnight to mate, and copulation was verified the following morning by the presence of sperm in vaginal smears.

On the first day of pregnancy, the dams were isolated in individual cages and sequentially divided into four groups, each receiving one of four diets: a control diet (C diet, $\mathrm{C}$ group), a control diet supplemented with oligofructose (CF diet, CF group), a diet enriched with hydrogenated vegetable fat ( $\mathrm{T}$ diet, $\mathrm{T}$ group) or a diet enriched with hydrogenated vegetable fat supplemented with oligofructose (TF diet, TF group). The diets were maintained throughout pregnancy and lactation. At birth, pups remained in the same group as the mother. The four diets were prepared according to the recommendations of the American Institute of Nutrition (AIN-93G) $[42,43]$ and bore a similar calorific and lipid content. The source of lipids for the $\mathrm{C}$ and $\mathrm{CF}$ diets was soybean oil, and the principal source for the $\mathrm{T}$ and $\mathrm{TF}$ diets was partially hydrogenated vegetable fat, which is rich in TFAs. The CF and TF diets were prepared by adding $100 \mathrm{~g} / \mathrm{kg}$ of oligofructose to the diet (Orafti P95, Pemuco, Chile). According to the manufacturer, the $\mathrm{OF}$ used in this study is a mixture of oligosaccharides extracted from chicory root. These oligosaccharides are composed of fructose units connected by $ß(2-1)$ links, and a glucose unit terminates a few of these molecules. The DP of oligofructose in this supplement ranges between 2 and 8 . The centesimal composition of the diets is presented in Table 1. Pisani et al. have previously described the fatty acid profile of $\mathrm{C}$ and $\mathrm{T}$ diets [8].

On the day of delivery, considered day 0 of lactation, litter sizes were adjusted to eight pups each. The pups were weighed and measured (naso-anal length) at birth and on postnatal days 7, 14 and 21.

\section{Experimental procedures}

The pups were euthanized by decapitation on postnatal day 21. The animals were not fasted to avoid weaning stress. Trunk blood was collected and then immediately centrifuged at $2500 \mathrm{rpm}$ for 15 minutes, and the serum was separated and stored at $-80^{\circ} \mathrm{C}$ for the determination of lipopolysaccharides (LPS) and free fatty acids (FFA). The retroperitoneal white adipose tissue (RET) and liver were isolated, weighed, immediately frozen in liquid nitrogen and stored at $-80^{\circ} \mathrm{C}$. The gut and faecal content were removed and separated into portions, the cecum and colon, and were immediately placed in liquid nitrogen for

Table 1 Composition of the control diet, control diet supplemented with oligofructose, diet enriched with trans fatty acids and diet enriched with trans fatty acids supplemented with oligofructose according to AIN-93

\begin{tabular}{ccccc}
\hline & & \multicolumn{3}{c}{ Diet $\mathbf{( g / 1 0 0 ~ g ) ~}$} \\
\hline Ingredient & C & CF & T & TF \\
Casein* & 20.0 & 20.0 & 20.0 & 20.0 \\
L-cystinet & 0.3 & 0.3 & 0.3 & 0.3 \\
Cornstarcht & 62.0 & 52.0 & 62.0 & 52.0 \\
Soybean oilł & 8.0 & 8.0 & 1.0 & 1.0 \\
Hydrogenated vegetablefat\$ & - & - & 7.0 & 7.0 \\
Butylhydroquinonet & 0.0014 & 0.0014 & 0.0014 & 0.0014 \\
Mineral mixture§ & 3.5 & 3.5 & 3.5 & 3.5 \\
Vitamin mixture\# & 1.0 & 1.0 & 1.0 & 1.0 \\
Celluloset & 5.0 & 5.0 & 5.0 & 5.0 \\
Choline bitartrate† & 0.25 & 0.25 & 0.25 & 0.25 \\
Oligofructose£ & - & 10.0 & - & 10.0 \\
Energy (kcal/g) & 4.0 & 4.0 & 4.0 & 4.0 \\
\hline
\end{tabular}

${ }^{*}$ Casein was obtained from Labsynth, São Paulo, Brazil.

tL-cystine, cornstarch, butylhydroquinone, cellulose and choline bitartrate were obtained from Viafarma, São Paulo, Brazil. ‡Oil was supplied from soybean (Lisa/Ind. Brazil).

\$Hydrogenated vegetable fat was supplied from Unilever, São Paulo, Brazil. \$Mineral mix $9 \mathrm{mg} / \mathrm{kg}$ diet): calcium, 5000; phosphorus, 1561; potassium, 3600; sodium, 1019; chloride, 1571; sulfur, 300; magnesium, 507; iron, 35; copper, 6.0; manganese, 10.0; zinc, 30.0; chromium, 1.0; iodine 0.2; selenium, 0.15; fluoride, 1.00; boron, 0.50; molybdenum, 0.15; silicon, 5.0; nickel, 0.5; lithium, 0.1; vanadium, 0.1 (AIN-93G, mineral mix, Rhoster, Brazil).

\#Vitamin mix (mg/kg diet): thiamin HCL, 6.0, riboflavin, 6.0; pyridoxine $\mathrm{HCL} 7.0$; niacin, 30.0; calcium pantothenate, 16.0; folic acid, 2.0; biotin, 0.2; vitamin B12,25.0; vitamin A palmitate $4000 \mathrm{IU}$; vitamin E acetate, 75; vitamin D3, $1000 \mathrm{IU}$; vitamin KI, 0.75. (AIN-93G, vitamin mix, Rhoster, Brazil). £Oligofructose (P95) was manufactured by Orafti (Pemuco, Chile) and was obtained by Viafarma, São Paulo, Brazil. 
the subsequent analysis of the colon bacterial DNA by real-time PCR (RT-PCR).

\section{Serum determination of lipopolysaccharides and free fatty acids}

The concentration of LPS in serum was analysed using the Limulus Amebocyte Lysate (LAL) assay, a quantitative chromogenic test for detecting endotoxins (LAL QCL-1000 assay, Lonza, Walkersville, MD, USA). Serum samples were diluted 10 times with pyrogen-free water and incubated in pyrogen-free tubes at $75^{\circ} \mathrm{C}$ for $5 \mathrm{mi}$ nutes. All the materials used in the test were initially autoclaved to render them pyrogen-free and to avoid interference in the test. The standard curve used in the assay was generated with known concentrations of LPS of the strain Escherichia coli O111:B4. The free fatty acids in the serum were determined with a 96-well Serum/Plasma Fatty Acid Kit Non-Esterified Fatty Acids 500 Point Detection Kit (Zenbio Inc., Research Triangle Park, NC, USA), following a 20-fold dilution of the samples. The manufacturer's recommendations, which are listed in the protocols accompanying the product, were followed for the analysis.

\section{Genomic DNA extraction from faecal samples and real-time polymerase chain reaction}

Genomic DNA from faecal samples of colon was extracted with the QiagenQIAmp DNA Stool Minikit (Qiagen, Valencia, CA, USA), according to the manufacturer's recommendations. The DNA concentration per microlitre was measured using a spectrophotometer, NanoDrop ND-1000 (NanoDrop Technologies Inc., Wilmington, EUA), and the readings were acquired at wavelengths of 260, 280 and $230 \mathrm{~nm}$. The purity was estimated by the $260 / 280 \mathrm{~nm}$ ratio, which must range between 1.8 and 2.0 for nucleic acids. All samples were maintained at $-80^{\circ} \mathrm{C}$.

Lactobacillus spp. was quantified by RT-PCR. Relative levels of lactobacillus spp. DNA were quantified in real time, using a SYBR Green primer in an ABI Prism 7500 Sequence Detector (both from Applied Biosystems, Foster City, CA, USA). Relative levels of the housekeeping gene of all bacteria were measured. The primers used were: lactobacillus spp., 5'- AGC AGT AGG GAA TCT TCC A-3' (sense) and 5' -CAC CGC TAC ACA TGG AG-3' (antisense), and all bacteria, 5'-TCC TAC GGG AGG CAG CAG T-3' (sense) and 5'-GAC TAC CAG GGT ATC TAA TCC TGT T-3' (antisense). The results were obtained using the Sequence Detector software (Applied Biosystems) and were expressed as the relative increase using the method of $2^{-\Delta \Delta \mathrm{Ct}}$, described by Livak and Schmittgen [44].

\section{Statistical analysis}

Data were submitted to quality tests, the Shapiro-Wilk (normality), Levenne (homogeneity) and/or Mauchly (sphericity) test, and were standardised to the Z score if necessary. Non-spherical data were corrected using F-values (Greenhouse-Geisser). The statistical significance of the differences between the means of the four group was assessed using a two-way analysis of variance (ANOVA) or ANOVA for repeated measure, followed by a Bonferroni post hoc test. All statistical tests were performed using the PASW Statistics 18 program, except for the comparison between $\mathrm{C}$ and $\mathrm{TF}$ groups, which was performed in the Stats Direct program using a one-way ANOVA and a Bonferroni post hoc test. The other functions were executed using the Microsoft Excel 2010 program. All results are presented as the means \pm standard error of the mean (SEM), and differences were considered to be significant when $p \leq 0.05$.

\section{Results}

Body weight, body weight gain and animal length

Over the entire period of treatment, the mean body weights (BWs) of the 21-d-old pups in the CF and TF groups were significantly lower than those of the $\mathrm{C}$ group ( $p \leq 0.01$ and $p<0.0001$, respectively). Additionally, the TF group presented lower BWs than the $\mathrm{T}(p<0.001)$ group during all of the experimental treatments. At birth, the BWs of the T group were significantly higher compared to the $\mathrm{C}(p=0.001)$ group; however, by the second and third weeks of treatment, the $C$ group had higher BWs compared to the T group $(p \leq 0.002)$. By postnatal days 7 and 14 , the BW in the TF group was lower than the CF group $(p \leq 0.003)$ (Figure 1A).

Similarly, during all of the treatments, the BW gain of the offspring in the CF and TF groups was significantly lower than the $\mathrm{C}$ group $(p<0.001$ and $p<0.0001$, respectively). During the first and second week, the 21-dold pups of the TF group presented a lower BW gain compared to the $\mathrm{T}(p<0.02)$ group. By the second and third week, body weight gain in the $C$ group was significantly higher compared to the $\mathrm{T}(p \leq 0.003)$ group. Furthermore, the TF group presented a lower BW gain than the CF group $(p<0.001)$ during the first week of treatment (Figure 1C).

Figure $1 \mathrm{~B}$ shows that in the CF and TF groups, the length of the 21-d-old pups during the entire treatment was significantly lower than the $\mathrm{C}$ group $(p \leq 0.002$ and $p<0.0001$, respectively). Likewise, the TF group presented lower lengths than the T group $(p<0.001)$ over the entire experimental period. At birth, the $\mathrm{T}$ group presented greater lengths compared to the $C$ group $(p=0.004)$; however, at postnatal day 21 , the length of the $\mathrm{C}$ group was significantly higher in relation to the $\mathrm{T}$ group $(p<0.001)$. Finally, by postnatal days 7 and 14 , the TF group presented smaller lengths than the CF group $(p \leq 0.003)$ (Figure $1 \mathrm{~B})$. 

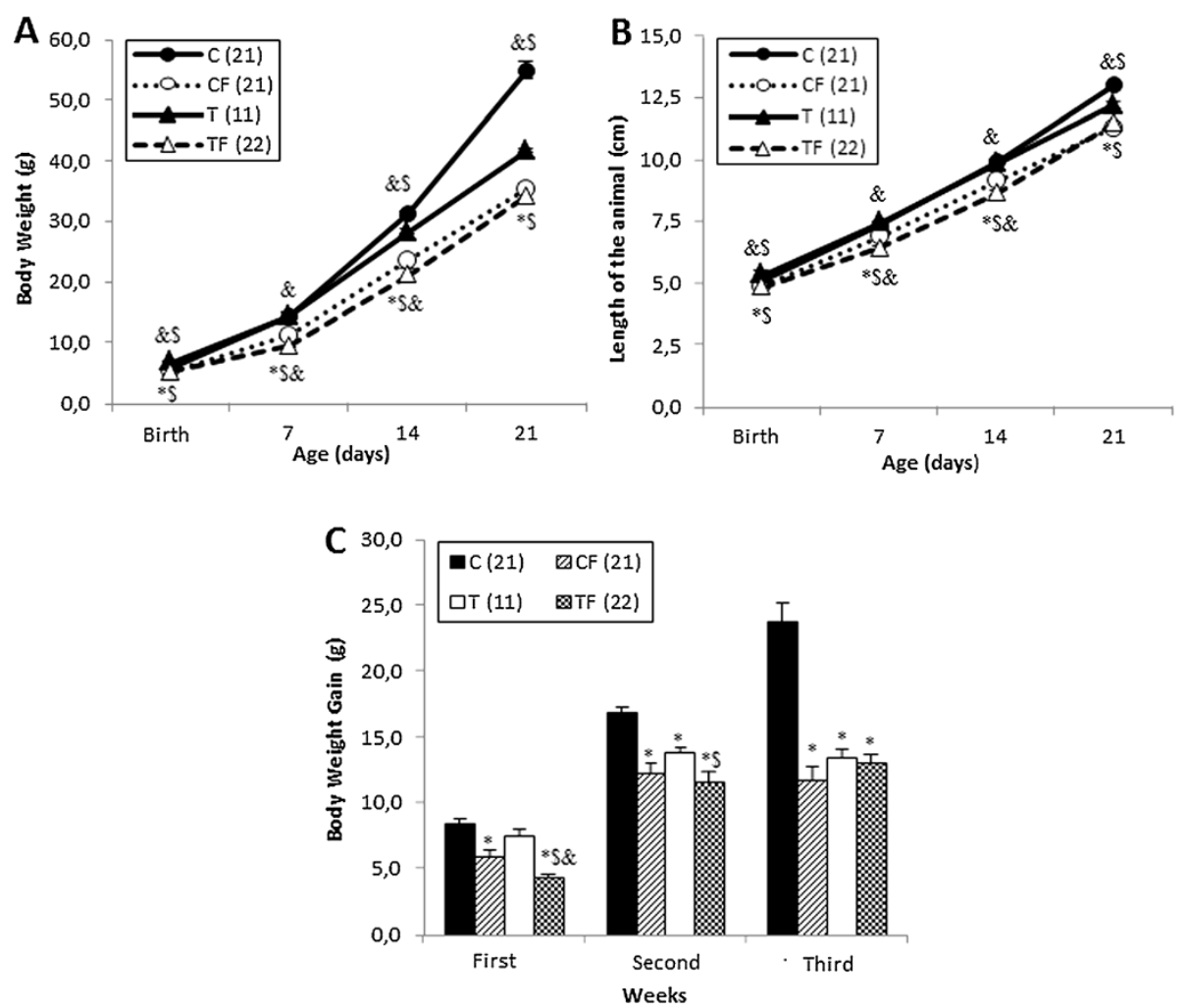

Figure 1 Body weight (A), length of the animal (B) and body weight gain (C). C -offspring of dams fed control diet; CF - offspring of dams fed control diet supplemented with oligofructose; T - offspring of dams fed diet enriched with hydrogenated vegetable fat; TF - offspring of dams fed diet enriched with hydrogenated vegetable fat supplemented with oligofructose. The number in parentheses refers to the sample value. Data are means \pm SEMs. $p \leq 0.05$ versus $C . \& p \leq 0.05$ versus CF. ${ }^{\$} p \leq 0.05$ versus T. ${ }^{*} p \leq 0.05$ versus TF.

\section{Relative weight of tissues}

The relative RET weight in the CF and $\mathrm{T}$ groups was significantly lower than the $\mathrm{C}$ group $(p<0.001)$. Moreover, the TF group presented a lower relative RET weight compared to the CF $(p=0.003)$ and $C(p<0.0001)$ groups (Table 2$)$.

The relative weight of the liver in the TF group was significantly lower than the $\mathrm{T}(p=0.003)$ and $\mathrm{C}(p=0.041)$ groups (Table 2).

\section{Serum concentration of lipopolysaccharides and free fatty} acids

The serum concentration of LPS in the CF group was significantly higher than the $\mathrm{C}$ group $(p=0.05)$ (Figure 2A).

Figure $2 \mathrm{~B}$ shows that the FFA serum concentration in the CF, $\mathrm{T}$ and $\mathrm{TF}$ groups was lower compared to the $\mathrm{C}$ ( $p=0.001, p=0.03$ and $p<0.0002$, respectively) group.
Further, the FFA serum concentration in the TF group was lower than the $\mathrm{T}$ group $(p=0.018)$.

Levels of lactobacillus spp. in colon

The genomic DNA levels of the lactobacillus spp. in the faecal content of the colon of the CF group were 2.23fold higher than the $\mathrm{C}$ group $(p=0.02)$ in 21-d-old offspring (Figure 3 ) and also in the TF group compared with the $\mathrm{C}$ group; however, this difference was not significant.

\section{Discussion}

In the present study, supplementing the dam's diet with $10 \%$ oligofructose during pregnancy and lactation decreased the body weight, body weight gain, length, relative weight of tissues and serum free fatty acids, which

Table 2 Relative weight of retroperitoneal adipose tissue and liver in $\mathbf{2 1 d}$-old pups

\begin{tabular}{|c|c|c|c|c|}
\hline Relative weight (g/100 g body weight) & $C(n=13)$ & $C F(n=15)$ & $T(n=9)$ & TF $(n=13)$ \\
\hline RET & $0,376 \pm 0,028$ & $0,256 \pm 0,028^{* \#}$ & $0,152 \pm 0,022^{*}$ & $0,156 \pm 0,006^{* \&}$ \\
\hline LIVER & $3,562 \pm 0,074$ & $3,424 \pm 0,128$ & $3,792 \pm 0,068$ & $3,315 \pm 0,088^{* \$}$ \\
\hline
\end{tabular}

C - offspring of dams fed control diet; CF - offspring of dams fed control diet supplemented with oligofructose; $\mathrm{T}$ - offspring of dams fed diet enriched with hydrogenated vegetable fat; TF - offspring of dams fed diet enriched with hydrogenated vegetable fat supplemented with oligofructose. The number in parentheses refers to the sample value. Data are means \pm SEMs. ${ }^{*} p \leq 0.05$ versus $C .{ }^{\&} p \leq 0.05$ versus $C F$. ${ }^{\$} p \leq 0.05$ versus T. ${ }^{\#} p \leq 0.05$ versus TF. 

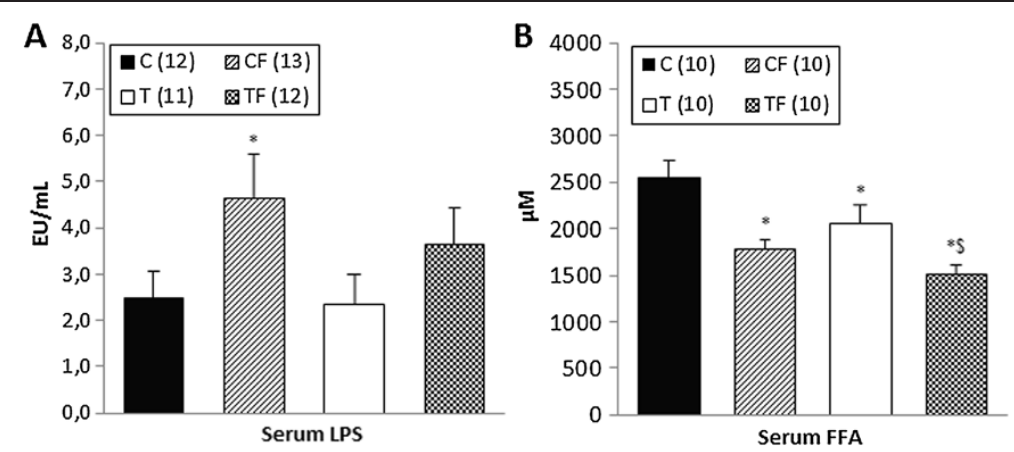

Figure 2 Serum concentration of lipopolysaccharides (LPS) (A) and serum concentration of free fatty acids (FFA) (B). C - offspring of dams fed control diet; CF -offspring of dams fed control diet supplemented with oligofructose; T - offspring of dams fed diet enriched with hydrogenated vegetable fat; TF - offspring of dams fed diet enriched with hydrogenated vegetable fat supplemented with oligofructose. The number in parentheses refers to the sample value. Data are means \pm SEMs. ${ }^{*} p \leq 0.05$ versus $C . \& p \leq 0.05$ versus $C F$. ${ }^{\$} p \leq 0.05$ versus T. \# $\mathrm{p} \leq 0.05$ versus TF.

was accompanied by an increase in the serum concentration of lipopolysaccharides and lactobacillus spp. genomic DNA levels in the colon of the 21-d-old pups.

These results indicate that the supplementation of the dam's diet with high amounts of oligofructose (10\%) during pregnancy and lactation adversely affects the development and increases endotoxemia, possibly by bacterial translocation in the offspring.

The 21-d-old pups of the CF and TF groups presented lower body weights and lengths compared to the $\mathrm{C}$ and $\mathrm{T}$ groups (Figure 1), which were accompanied by a reduction in the free fatty acid serum concentration (Figure 2) and relative weights of the RET and liver (Table 2). Additionally, a lower body weight gain was also observed in the offspring of the CF group throughout the entire experimental period and in the TF group during the first and second weeks of treatment (Figure 1).

A literature review presents a limited and controversial picture of the effects of high-fibre diets during pregnancy and lactation. Corroborating our results, Carabin and Flamm reported a delay in the growth of pups from dams fed with $20 \%$ FOS diet during pregnancy and lactation [16]. On the other hand, previous studies did not demonstrate the negative effects of FOS supplementation during pregnancy on offspring development $[16,45]$. Furthermore, Pisani et al. showed that trans fatty acid

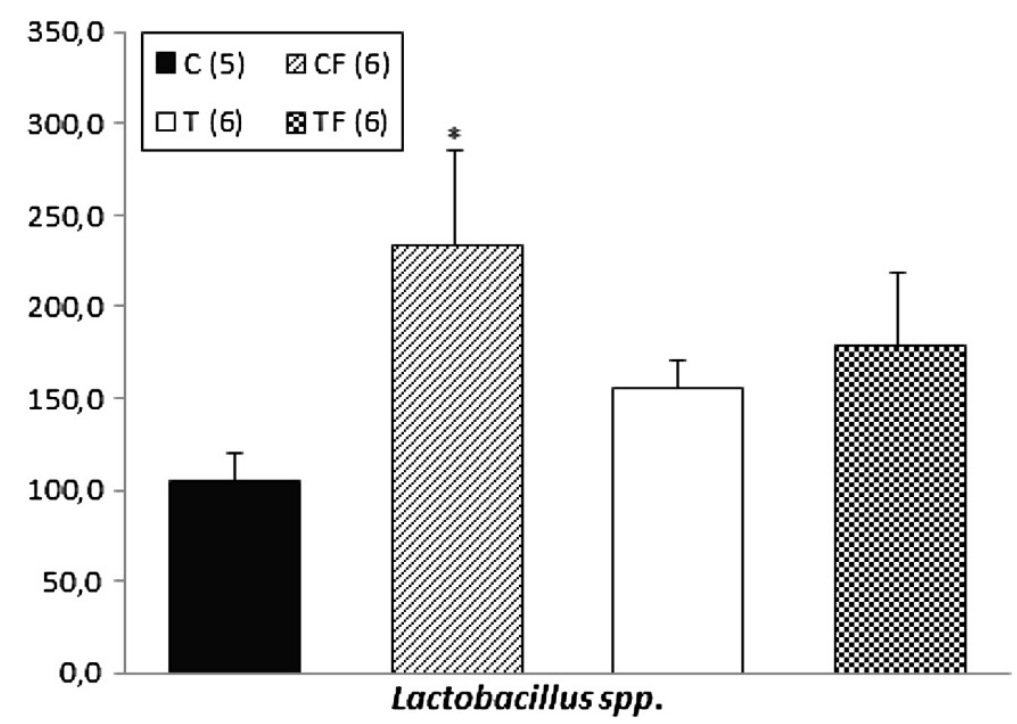

Figure 3 Lactobacillus spp. genomic DNA levels on fecal content in colon. C - offspring of dams fed control diet; CF - offspring of dams fed control diet supplemented with oligofructose; T - offspring of dams fed diet enriched with hydrogenated vegetable fat; TF - offspring of dams fed diet enriched with hydrogenated vegetable fat supplemented with oligofructose. The number in parentheses refers to the sample value. Data are means \pm SEMs. Results are expressed in arbitrary units, stipulating 100 as the control value. ${ }^{*} p \leq 0.05$ versus C. \&p $\leq 0.05$ versus CF. ${ }^{\$} p \leq 0.05$ versus $T$. ${ }^{\#} p \leq 0.05$ versus TF. 
intake during pregnancy and lactation did not modify the body weight of the pups during the entire period of lactation [10]. Thus, it could be concluded that high FOS supplementation during pregnancy and lactation could harm offspring development.

In our study, the birth weights of the offspring were affected by a trans fatty acid diet and 10\% OF supplementation during pregnancy and lactation (Figure 1). In this regard, Hallam and Reimer reported that dietary supplementation with $21.6 \%$ prebiotic fibres (inulin and oligofructose mixture) during pregnancy and lactation decreased the birth weight of female offspring, whereas the birth weights of male offspring did not change. In the same study, the authors also demonstrated that there were no differences in the naso-anal length within male or female pups; however, the percentage of body fat at 4 weeks of age was lower in the high-fibre offspring [46]. Additionally, Maurer and Reimer did not observe any differences in the birth weight or body weight of the pups at postnatal days 7,14 and 21 from dams fed a control, high-fibre (a combination of inulin and oligofructose) or high-protein diet during pregnancy and lactation [47]. Rodenburg et al. reported no difference in the body weight gain of 8-week-old rats fed a diet containing 6\% FOS for 16 days [48]. Similarly, Parnell and Reimer showed that a high-fibre diet $(10 \%$ and $20 \%$ of inulin and oligofructose) for 10 weeks did not influence the body weight and the fat mass in 8-week-old rats; however, the total liver weight decreased in the obese animals fed a diet supplemented with fibre prebiotics [49].

In accordance with results of corporal composition, we believe that the decrease in FFA serum concentration of the pups (Figure 2) reflects the reduction in the body weight (Figure 1) and RET-relative weight (Table 2) on the $\mathrm{CF}, \mathrm{T}$ and $\mathrm{TF}$ groups compared to the $\mathrm{C}$ group. Adipose tissue is considered a major site of fatty acid storage in the body. In this regard, visceral fat depots, such as retroperitoneal adipose tissue, participate in the regulation of FFAs release to systemic circulation under several physiologic conditions [50]. Shadid and Jensen reported that weight loss by diet and exercise is associated with a decrease in FFA flux [51]. On the other hand, studies demonstrated that prebiotics are able to decrease the hepatic lipogenesis by a reduction in the activity and gene expression of hepatic lipogenic enzymes, such as fatty acid synthase (FAS) [18,52]. Kok et al. showed that oligofructose supplementation $(100 \mathrm{~g} / \mathrm{kg}$ of diet) for 30 days decreased the activity of the FAS enzyme in male Wistar rats [53]. In contrast, Parnell and Reimer demonstrated that high-fibre diets (10\% and 20\% of inulin and oligofructose, respectively) for 10 weeks increased FAS hepatic gene expression in JCR:La-cp rats [49]. Furthermore, studies demonstrated that dietary supplementation with prebiotic fibres during pregnancy and lactation (21,6\%; inulin and oligofructose mixture) does not alter FAS gene expression in the liver and brown adipose tissue and does not reduce the FFA plasma concentration in the offspring $[46,47]$.

Moreover, the changes in a pup's body weight evolution and length of the CF and TF groups compared to the $\mathrm{C}$ and $\mathrm{T}$ groups (Figure 1) accompanied by a reduction in the liver relative weight of the TF group compared to the T group (Table 2) are consistent with the hypothesis that the $10 \%$ oligofructose supplementation during pregnancy and lactation contributes to offspring malnutrition, most likely as a consequence of impaired somatic and morphologic development. Taken together, these results suggest that the amount and type of the ingested prebiotic as well as the treatment period and physiological conditions could influence the development of the animal.

Finally, our results established that the 21-d-old offspring of the CF group had a higher lipopolysaccharide serum concentration (Figure 2), accompanied by a 2.23fold increase in lactobacillus spp. genomic DNA levels in the faecal content of the colon (Figure 3) compared to the $\mathrm{C}$ group.

The inulin-type fructans are known to selectively stimulate the growth and the activity of the lactobacillus present in the colonic microbiota, thereby modulating the intestinal environment through changes in intestinal permeability, bacterial composition and SCFA production and contributing to the reduction in the LPS serum concentration, which benefits the host's health $[32,54,55]$. In fact, Parnell and Reimer reported an increase in the lactobacillus spp. levels of 8-week-old obese rats fed a highfibre diet (20\% of inulin and oligofructose) for 10 weeks [56]. Mangell et al. demonstrated that Lactobacillus plantarum 299v can reduce Escherichia coli-induced intestinal permeability [57]. Additionally, the authors showed a reduction in the bacterial translocation to the liver and mesenteric lymph node of the rats pretreated with Lactobacillus plantarum $229 v$ for one week before intraperitoneal injection of LPS [58]. Rodes et al. demonstrated that the administration of Lactobacillus rhamnosus and Lactobacillus reuteri in an in vitro human colonic microbiota model decreased LPS concentrations in a timedependent manner [59].

On the other hand, in accordance with our data, Ten Bruggencate et al. showed that a low calcium diet supplemented with FOS $(60 \mathrm{~g} / \mathrm{kg}$ of diet) for two weeks stimulated the growth of lactobacilli on cecal and colonic mucosa, accompanied by an increase in the intestinal permeability and translocation of Salmonella enteritidis in 8-wk-old Wistar rats [60]. Similarly, Ten Bruggencate et al. also demonstrated that the daily FOS consumption (20 g/day) associated with lower calcium intake during two weeks by healthy men increased the number of 
faecal lactobacillus, faecal mucin excretion and total faecal lactic acid excretion. The authors suggested that the mucin secretion induced by rapid production of organic acids (lactate and SCFA), in response to excessive prebiotic fermentation, is related to the irritation and impairment of the intestinal barrier function [61].

Another study demonstrated a dose-dependent increase in the colonisation and translocation of Salmonella enteritidis, accompanied by a higher lactic acid concentration in cecal contents in the FOS supplemented group (6\% and $3 \%$ ) in 8 -wk-old Wistar rats; however, no changes were reported in the number of faecal lactobacilli [62]. Likewise, Rodenburg et al. observed an increase in the intestinal permeability and in the mitochondrial gene expression in 8-week-old rats submitted to a 16-day diet, low in calcium and supplemented with FOS (6\%). In this study, the authors proposed that the rapid FOS fermentation by the colonic microbiota, resulting in acid lactic accumulation, excessive organic acids production and decreased luminal $\mathrm{pH}$, leads to acidification of the cellular cytoplasm and indirectly induces ATP-depletion, which consequently increases the expression of colonic mitochondrial genes that may be involved in the maintenance of the intestinal barrier because disrupted energy metabolism leads to increases in intestinal permeability [48].

Accordingly, we observed that $10 \%$ FOS supplementation triggered diarrhoea in dams during the treatment (data not shown), which may be associated with the calcium loss. Additionally, it is possible that the oligosaccharides present in maternal milk $[39,40]$ and the maternal intestinal bacteria transferred to the offspring through the breast milk [41] may lead to excessive production and luminal accumulation of organic acids in the pup's gut, altering intestinal permeability and bacterial composition in the 21-d-old offspring [48,60-62]. Thus, changes in the composition of the microbiota and increases in intestinal permeability, along with damage to the intestinal barrier integrity, can cause an increase in bacterial translocation and LPS serum concentration, resulting in TLR4-mediated inflammatory responses in the offspring [32].

In fact, we previously showed that $10 \%$ oligofructose supplementation during pregnancy and lactation increased the TNF- $\alpha$ content in the liver of pups in the CF group and IL- 6 and TNF- $\alpha$ contents in RET of pups in the TF group, accompanied by a reduction in the serum adiponectin concentrations of the offspring in the CF, $\mathrm{T}$ and TF groups [63].

\section{Conclusion}

In conclusion, supplementation with $10 \%$ oligofructose during pregnancy and lactation, in the presence or absence of hydrogenated vegetable fat harms offspring development and increases endotoxemia, most likely due to damage to the intestinal permeability, changes in colonic bacterial population and impairment of the intestinal mucosal barrier integrity, which promotes an increase in serum concentrations of lipopolysaccharides in 21-d-old pups. Further studies are needed to investigate the dosedependent effects of oligofructose ingestion during gestation and lactation as well as on the development, metabolism and endotoxemia of the pups.

\section{Competing interests}

The authors declare that they have no competing interests.

\section{Authors' contribution}

LVM - designed the study, carried out the experiments, performed the statistical analysis and drafted the manuscript. LMO- helped to carried out the experiments, revised and helped to draft the manuscript. JLO - participated in the design of the study helped to carried out the experiments. ACLH - participated in the design of the study helped to carried out the experiments. ABS - helped to carried out the experiments. AAS - helped to carried out the experiments. $\mathrm{MHO}$ - helped to perform the statistical analysis. EBR - helped to draft the manuscript. CMON - conceive the study, participated in its design, and helped to draft the manuscript. LPP - conceive the study, participated in its design, and helped to draft the manuscript. All authors read and approved the final manuscript.

\section{Acknowledgments}

This research was supported by CAPES (Coordenação de Aperfeiçoamento de Pessoal de Nível Superior), CNPq (Conselho Nacional de Desenvolvimento Científico e Tecnológico) and FAPESP (Fundação de Amparo à Pesquisa do Estado de São Paulo, n²011/19426-2). The authors gratefully acknowledge the invaluable assistance of Mauro Cardoso Pereira for the animal care.

\section{Author details}

${ }^{1}$ Programa de Pós Graduação Interdisciplinar em Ciências da Saúde, Universidade Federal de São Paulo, Santos, SP, Brazil. ²Departamento de Biociências, Instituto de Saúde e Sociedade, Universidade Federal de São Paulo, Rua Silva Jardim, 136, Térreo, Vila Mathias, Santos, SP, Brazil.

${ }^{3}$ Departamento Fisiologia, Disciplina de Fisiologia da Nutrição, Escola Paulista de Medicina, Universidade Federal de São Paulo, Rua Botucatu, 862, $2^{\circ}$ andar, Vila Clementino, São Paulo, SP, Brazil.

Received: 20 December 2013 Accepted: 14 January 2014

Published: 5 February 2014

\section{References}

1. Barker DJ: In utero programming of chronic disease. Clin Sci (Lond) 1998, 95(2):115-128.

2. Godfrey KM: Maternal regulation of fetal development and health in adult life. Eur J Obstet Gynecol Reprod Biol 1998, 78(2):141-150.

3. Godfrey KM, Suppl A: The role of the placenta in fetal programming - a review. Placenta 2002, 23:S20-27.

4. Morley R, Dwyer T: Fetal origins of adult disease? Clin Exp Pharmacol Physiol 2001, 28(11):962-966.

5. Champ M, Hoebler C: Functional food for pregnant, lactating women and in perinatal nutrition: a role for dietary fibres? Curr Opin Clin Nutr Metab Care 2009, 12(6):565-574

6. Gebauer SK, Psota TL, Kris-Etherton PM: The diversity of health effects of individual trans fatty acid isomers. Lipids 2007, 42(9):787-799.

7. Mozaffarian D, Pischon T, Hankinson SE, Rifai N, Joshipura K, Willett WC, Rimm EB: Dietary intake of trans fatty acids and systemic inflammation in women. Am J Clin Nutr 2004, 79(4):606-612.

8. Pisani LP, Oyama LM, Bueno AA, Biz C, Albuquerque KT, Ribeiro EB, Oller do Nascimento CM: Hydrogenated fat intake during pregnancy and lactation modifies serum lipid profile and adipokine mRNA in 21-day-old rats. Nutrition 2008, 24(3):255-261.

9. de Oliveira JL, Oyama LM, Hachul AC, Biz C, Ribeiro EB, Oller do Nascimento CM, Pisani LP: Hydrogenated fat intake during pregnancy and lactation caused increase in TRAF- 6 and reduced AdipoR 1 in white adipose tissue, 
but not in muscle of 21 days old offspring rats. Lipids Health Dis 2011, 10:22.

10. Pisani $L P$, Nascimento $C M O$ d, Bueno $A A, B i z C$, Albuquerque KT, Ribeiro EB, Oyama LM: Hydrogenated fat diet intake during pregnancy and lactation modifies the PAl-1 gene expression in white adipose tissue of offspring in adult life. Lipids Health Dis 2008, 7:13.

11. Osso FS, Moreira ASB, Teixeira MT, Pereira RO, Tavares do Carmo MG, Moura AS: Trans fatty acids in maternal milk lead to cardiac insulin resistance in adult offspring. Nutrition 2008, 24(7-8):727-732.

12. Skurk $\mathrm{T}$, Hauner $\mathrm{H}$ : Obesity and impaired fibrinolysis: role of adipose production of plasminogen activator inhibitor-1. Int J Obes Relat Metab Disord 2004, 28(11):1357-1364.

13. Hajer GR, van Haeften TW, Visseren FL: Adipose tissue dysfunction in obesity, diabetes, and vascular diseases. Eur Heart J 2008, 29(24):2959-2971.

14. Giordano P, Del Vecchio GC, Cecinati V, Delvecchio M, Altomare M, De Palma F, De Mattia D, Cavallo L, Faienza MF: Metabolic, inflammatory, endothelial and haemostatic markers in a group of Italian obese children and adolescents. Eur J Pediatr 2011, 170(7):845-850.

15. Pimentel GD, Lira FS, Rosa JC, Oliveira JL, Losinskas-Hachul AC, Souza GI, das Graças T, do Carmo M, Santos RV, de Mello MT, Tufik S, Seelaender M, Oyama LM, Nascimento CM O d, Watanabe RH, Ribeiro EB, Pisani LP: Intake of trans fatty acids during gestation and lactation leads to hypothalamic inflammation via TLR4/NFkBp65 signaling in adult offspring. J Nutr Biochem 2012, 23(3):265-271.

16. Carabin IG, Flamm WG: Evaluation of safety of inulin and oligofructose as dietary fiber. Regul Toxicol Pharmacol 1999, 30(3):268-282.

17. Brighenti F: Dietary fructans and serum triacylglycerols: a meta-analysis of randomized controlled trials. J Nutr 2007, 137(11):2552S-2556S.

18. Delzenne NM, Daubioul C, Neyrinck A, Lasa M, Taper HS: Inulin and oligofructose modulate lipid metabolism in animals: review of biochemical events and future prospects. Br J Nutr 2002, 87(Suppl 2):S255-S259.

19. Kok NN, Taper HS, Delzenne NM: Oligofructose modulates lipid metabolism alterations induced by a fat-rich diet in rats. $J$ App/ Toxicol 1998, 18(1):47-53.

20. Roberfroid MB: Introducing inulin-type fructans. Br J Nutr 2005, 93(Suppl 1):S13-S25.

21. Roberfroid MB: Inulin-type fructans: functional food ingredients. J Nutr 2007, 137(11 Suppl):2493S-2502S.

22. Kelly G: Inulin-type prebiotics-a review: part 1. Altern Med Rev 2008, 13(4):315-329.

23. Kaur N, Gupta AK: Applications of inulin and oligofructose in health and nutrition. J Biosci 2002, 27:703-714.

24. Cherbut $\mathrm{C}$ : Inulin and oligofructose in the dietary fibre concept. Br I Nut 2002, 87(Suppl 2):S159-S162.

25. Kleessen B, Hartmann L, Blaut M: Oligofructose and long-chain inulin: influence on the gut microbial ecology of rats associated with a human faecal flora. Br J Nutr 2001, 86(2):291-300.

26. Roberfroid MB: Chicory fructooligosaccharides and the gastrointestinal tract. Nutrition 2000, 16(7-8):677-679.

27. Ley RE, Lozupone CA, Hamady M, Knight R, Gordon J: Worlds within worlds: evolution of the vertebrate gut microbiota. Nat Rev Microbiol 2008, 6(10):776-788

28. Gibson GR, Roberfroid MB: Dietary modulation of the human colonic microbiota: introducing the concept of prebiotics. J Nutr 1995, 125(6):1401-1412.

29. Krznarić Z, Vranešić Bender D, Kunović A, Kekez D, Stimac D: Gut microbiota and obesity. Dig Dis 2012, 30(2):196-200.

30. Kim KA, Gu W, Lee IA, Joh EH, Kim DH: High fat diet-induced gut microbiota exacerbates inflammation and obesity in mice via the TLR4 signaling pathway. PLoS One 2012, 7(10):e47713.

31. Cani PD, Neyrinck AM, Fava F, Knauf C, Burcelin RG, Tuohy KM, Gibson GR, Delzenne NM: Selective increases of bifidobacteria in gut microflora improve high-fat-diet-induced diabetes in mice through a mechanism associated with endotoxaemia. Diabetologia 2007, 50(11):2374-2383.

32. Nakamura YK, Omaye ST: Metabolic diseases and pro- and prebiotics: mechanistic insights. Nutr Metab (Lond) 2012, 9(1):60.

33. Shi H, Kokoeva MV, Inouye K, Tzameli I, Yin H, Flier JS: TLR4 links innate immunity and fatty acid-induced insulin resistance. J Clin Invest 2006, 116(11):3015-3025
34. Boden G, She P, Mozzoli M, Cheung P, Gumireddy K, Reddy P, Xiang X, Luo $Z$, Ruderman N: Free fatty acids produce insulin resistance and activate the proinflammatory nuclear factor-kappaB pathway in rat liver. Diabetes 2005, 54(12):3458-3465.

35. Boden G: Obesity and free fatty acids. Endocrinol Metab Clin North Am 2008, 37(3):635-646.

36. Roberfroid MB, Delzenne NM: Dietary fructans. Annu Rev Nutr 1998, 18:117-143

37. Macfarlane GT, Macfarlane S: Fermentation in the human large intestine: its physiologic consequences and the potential contribution of prebiotics. J Clin Gastroenterol 2011, 45(Suppl 3):S120-127.

38. Leonel AJ, Alvarez-Leite Jl: Butyrate: implications for intestinal function. Curr Opin Clin Nutr Metab Care 2012, 15(5):474-479.

39. Rudloff S, Kunz C: Milk oligosaccharides and metabolism in infants. Adv Nutr 2012, 3(3):398S-405S.

40. Kunz C, Rudloff S, Baier W, Klein N, Strobel S: Oligosaccharides in human milk: structural, functional, and metabolic aspects. Annu Rev Nutr 2000, 20:699-722

41. Fernández L, Langa S, Martín V, Maldonado A, Jiménez E, Martín R, Rodríguez JM: The human milk microbiota: origin and potential roles in health and disease. Pharmacol Res 2013, 69(1):1-10.

42. Reeves PG, Nielsen FH, Fahey GC Jr: AIN-93 purified diets for laboratory rodents: final report of the american institute of nutrition ad hoc writing committee on the reformulation of the AIN-76A rodent diet. J Nutr 1993, 123(11):1939-1951.

43. Reeves PG: Components of the AIN-93 diets as improvements in the AIN-76A diet. J Nutr 1997, 127(5 Suppl):838S-841S.

44. Livak K, Schmittgen TD: Analysis of relative gene expression data using real-time quantitative $P C R$ and the 2 (-delta delta $C(T)$ ) method. Methods 2001, 25(4):402-408

45. Greg Kelly ND: Inulin-type prebiotics: a review (part 2). Altern Med Rev 2009, 14(1):36-55.

46. Hallam MC, Reimer RA: A maternal high-protein diet predisposes female offspring to increased fat mass in adulthood whereas a prebiotic fibre diet decreases fat mass in rats. Br J Nutr 2013, 110(9):1732-1741.

47. Maurer AD, Reimer RA: Maternal consumption of high-prebiotic fibre or -protein diets during pregnancy and lactation differentially influences satiety hormones and expression of genes involved in glucose and lipid metabolism in offspring in rats. Br J Nutr 2011, 105(3):329-338.

48. Rodenburg W, Keijer J, Kramer E, Vink C, van der Meer R, Bovee-Oudenhoven IM: Impaired barrier function by dietary fructo-oligosaccharides (FOS) in rats is accompanied by increased colonic mitochondrial gene expression. BMC Genomics 2008, 9:144.

49. Parnell JA, Reimer RA: Effect of prebiotic fibre supplementation on hepatic gene expression and serum lipids: a dose-response study in JCR:LA-cp rats. Br J Nutr 2010, 103(11):1577-1584.

50. Jensen MD: Role of body fat distribution and the metabolic complications of obesity. J Clin Endocrinol Metab 2008, 93(11 Suppl 1):S57-S63.

51. Shadid S, Jensen MD: Pioglitazone increases non-esterified fatty acid clearance in upper body obesity. Diabetologia 2006, 49(1):149-157.

52. Beylot M: Effects of inulin-type fructans on lipid metabolism in man and in animal models. Br J Nutr 2005, 93(Suppl 1):S163-168.

53. Kok NN, Roberfroid M, Robert A, Delzenne N: Involvement of lipogenesis in the lower VLDL secretion induced by oligofructose in rats. Br J Nutr 1996, 76(6):881-890.

54. Cummings JH, Macfarlane GT: Gastrointestinal effects of prebiotics. Br J Nutr 2002, 87(Suppl 2):S145-S151.

55. Pan XD, Chen FQ, Wu TX, Tang HG, Zhao ZY: Prebiotic oligosaccharides change the concentrations of short-chain fatty acids and the microbial population of mouse bowel. J Zhejiang Univ Sci B 2009, 10(4):258-263.

56. Parnell JA, Reimer RA: Prebiotic fibres dose-dependently increase satiety hormones and alter bacteroidetes and firmicutes in lean and obese JCR: LA-cp rats. Br J Nutr 2012, 107(4):601-613.

57. Mangell $P$, Nejdfors $P$, Wang M, Ahrné S, Weström B, Thorlacius H, Jeppsson B: Lactobacillus plantarum 299v inhibits escherichia coli-induced intestinal permeability. Dig Dis Sci 2002, 47(3):511-516.

58. Mangell $P$, Lennernäs $P$, Wang $M$, Olsson $C$, Ahrné $S$, Molin $G$, Thorlacius $H$ Jeppsson B: Adhesive capability of lactobacillus plantarum $299 \mathrm{v}$ is important for preventing bacterial translocation in endotoxemic rats. APMIS 2006, 114(9):611-618. 
59. Rodes L, Khan A, Paul A, Coussa-Charley M, Marinescu D, Tomaro-Duchesneau C, Shao W, Kahouli I, Prakash S: Effect of probiotics lactobacillus and Bifidobacterium on gut-derived lipopolysaccharides and inflammatory cytokines: an in vitro study using a human colonic microbiota model. J Microbiol Biotechnol 2013, 23(4):518-526.

60. Ten Bruggencate SJ, Bovee-Oudenhoven IM, Lettink-Wissink ML, Van der Meer R: Dietary fructooligosaccharides increase intestinal permeability in rats. J Nutr 2005, 135(4):837-842.

61. Ten Bruggencate SJ, Bovee-Oudenhoven IM, Lettink-Wissink ML, Katan MB, van der Meer R: Dietary fructooligosaccharides affect intestinal barrier function in healthy men. J Nutr 2006, 136(1):70-74.

62. Ten Bruggencate SJ, Bovee-Oudenhoven IM, Lettink-Wissink ML, Van der Meer R: Dietary fructo-oligosaccharides dose-dependently increase translocation of salmonella in rats. J Nutr 2003, 133(7):2313-2318.

63. Hachul AC, Mennitti LV, de Oliveira JL, Moreno MF, Okuda MH, Dos Santos B, Oyama LM, Ribeiro EB, do Nascimento CM, Pisani LP: Oligofructose supplementation (10\%) during pregnancy and lactation does not change the inflammatory effect of concurrent trans fatty acid ingestion on 21-day-old offspring. Lipids Health Dis 2013, 12:59.

doi:10.1186/1476-511X-13-26

Cite this article as: Mennitti et al:: Oligofructose supplementation during pregnancy and lactation impairs offspring development and alters the intestinal properties of 21-d-old pups. Lipids in Health and Disease 2014 13:26.

\section{Submit your next manuscript to BioMed Central and take full advantage of:}

- Convenient online submission

- Thorough peer review

- No space constraints or color figure charges

- Immediate publication on acceptance

- Inclusion in PubMed, CAS, Scopus and Google Scholar

- Research which is freely available for redistribution 